\title{
Estudo das propriedades físico-químicas do tucupi
}

Study of tucupi physicochemical properties

\author{
Renan Campos CHISTÉ ${ }^{1}$, Kelly de Oliveira COHEN², Suzy Sarzi OLIVEIRA ${ }^{3}$
}

\section{Resumo}

O objetivo deste trabalho foi realizar a caracterização físico-química e a quantificação do cianeto em amostras do produto "tucupi", comercializado na cidade de Belém - PA. Sendo o tucupi um alimento líquido, sua umidade se apresentou na faixa de 94,66 a 97,46\%, possuindo, portanto, de 5,36 a $2,55 \%$ de matéria-seca para tais valores. O teor de cinzas variou entre 0,18 e $1,08 \%$. A acidez total das amostras analisadas variou entre 3,92 e 10,66 meq NaOH. $100 \mathrm{~mL}^{-1}$. Com relação a proteínas, o tucupi apresentou teores baixos, entre 0,33 e $0,66 \%$. Os valores de $\mathrm{pH}$ variaram entre 3,00 e 4,35. Finalmente, verificou-se que o teor de cianeto livre ficou na faixa de 9,47 a 46,86 mg $\mathrm{HCN}$. $\mathrm{kg}^{-1}$, enquanto que o do cianeto total foi de 55,58 a $157,17 \mathrm{mg} \mathrm{HCN} \cdot \mathrm{kg}^{-1}$, apresentando variações significativas entre os produtos.

Palavras-chave: Manhiot esculenta Crantz; mandioca; cianeto.

\begin{abstract}
A study was made to characterize the physicochemical properties and quantify the free and total cyanide content of samples of "tucupi", a liquid extracted from bitter cassava (M. esculenta) and used as a sauce in the regional cuisine, sold in the city of Belém, state of Pará, Brazil. The moisture content ranged from 94.66 to $97.46 \%$, the dry portion therefore representing 2.55 to $5.36 \%$. The ash content varied from 0.18 to $1.08 \%$. Total acidity of the analyzed samples ranged from 3.92 to 10.66 meq NaOH. $100 \mathrm{~mL}^{-1}$. The product's protein content was found to be low, ranging from 0.33 to $0.66 \%$, while $\mathrm{pH}$ varied from 3.00 to 4.35 . As for the free cyanide content, this was found to range from 9.47 to $46.86 \mathrm{mg} \mathrm{HCN} . \mathrm{kg}^{-1}$, while the total cyanide showed wide variations among the samples, ranging from 55.58 to $157.17 \mathrm{mg} \mathrm{HCN} . \mathrm{kg}^{-1}$.

Keywords: Manhiot esculenta Crantz (Euphorbiaceae); cassava; cyanide.
\end{abstract}

\section{Introdução}

No Estado do Pará, a mandioca apresenta lugar de destaque na dieta alimentar de sua população, sendo consumida, principalmente, na forma de farinha, mas também é utilizada como matéria-prima para a elaboração de diversos pratos típicos.

Para as famílias na faixa de renda de menos de um salário mínimo, o consumo de mandioca e seus derivados representa em torno de $10 \%$ da despesa anual em alimentação. Ela só perde em importância para o feijão, que aparece com um consumo equivalente a $13 \%$ dessa despesa. Esses dados ratificam a importância do produto para as classes de renda mais baixa ${ }^{5}$.

Durante o processo de fabricação da farinha, as raízes de mandioca são trituradas e prensadas para a remoção de seu líquido. A massa prensada segue para a torração e o resíduo líquido, denominado de manipueira, é descartado ou transformado no tucupi. Segundo CAGNON et al. ${ }^{4}$, o tucupi é o molho parcialmente fermentado da manipueira, que fica em repouso por 1 ou 2 dias para a decantação do amido que é posteriormente removido, ocorrendo naturalmente a sua fermentação. Após esta etapa, é realizada uma fervura adicionando-se condimentos, obtendo-se assim o tucupi. Este geralmente é embalado em garrafas do tipo PET ou similar.

O tacacá e o pato no tucupi são exemplos de pratos típicos da Região Norte, muito apreciados por sua população, cujo

Recebido para publicação em 30/1/2006

Aceito para publicação em 18/7/2007 (001668)

Universidade do Estado do Pará - UEPA, Belém - PA, Brasil,

E-mail: renanchiste@gmail.com

Embrapa Recursos Genéticos e Biotecnologia, Parque Estação Biológica - PqEB

Av. W5 Norte (final), CP 02372, CEP 70770-900, Brasília - DF, Brasil,

E-mail:cohen@cenargen.embrapa.br

Embrapa Amazônia Oriental, Trav. Dr. Enéas Pinheiro, s/n, CP 48 ,

CEP 66095-100, Belém - PA, Brasil,

E-mail:suzy@cpatu.embrapa.br

*A quem a correspondência deve ser enviada ingrediente principal na sua formulação é o tucupi. De acordo com o IBGE ${ }^{9}$, o consumo anual per capita de tucupi em Belém, capital do Pará, é de 0,35 kg.

Informações na literatura técnico-científica com relação ao tucupi são escassas, sendo necessário que se faça uma avaliação das principais características físico-químicas deste produto, principalmente com relação ao teor de cianeto (ácido cianídrico), já que este produto é obtido através do processamento da mandioca brava, que possui alta concentração de ácido cianídrico.

Quanto ao seu potencial tóxico, as mandiocas podem ser classificadas em três categorias, com base em seu conteúdo cianogênico: a) inócuas: menos do que $50 \mathrm{mg} \mathrm{HCN} . \mathrm{kg}^{-1}$ raízes frescas; b) moderadamente venenosas: entre 50-100 mg HCN. kg ${ }^{-1}$ de polpa fresca; e perigosamente venenosas (mandioca brava): acima de $100 \mathrm{mg} \mathrm{HCN} . \mathrm{kg}^{-13}$.

Os principais problemas de saúde associados à dieta altamente rica em compostos cianogênicos incluem: hipertiroidismo, resultante do metabolismo do tiocianato no metabolismo do iodo; neuropatia atáxica tropical, uma desordem neurológica; e konzo, uma paralisia rápida e permanente ${ }^{12,15,13}$.

Diante do exposto, o objetivo deste trabalho foi realizar a caracterização físico-química e a quantificação do teor de cianeto em amostras comerciais de tucupi na cidade de Belém - PA.

\section{Material e métodos}

\subsection{Origem das amostras}

As amostras de tucupi foram adquiridas nas principais feiras e supermercados da cidade de Belém - PA, tendo sido selecionadas 10 (dez) amostras. 


\subsection{Análises físico-químicas}

As análises realizadas foram:

- $\mathrm{pH}$ - medido diretamente com o auxílio de um pHmetro;

- Umidade - evaporação prévia da amostra em banhomaria, seguida de secagem em estufa a $105^{\circ} \mathrm{C}$, de acordo com o método 31.1.02, da $\mathrm{AOAC}^{1}$;

- Teor de cinzas - evaporação prévia da amostra em banhomaria, seguido de incineração em forno-mufla a $560{ }^{\circ} \mathrm{C}$, de acordo com o método 31.1.04, da $\mathrm{AOAC}^{1}$;

- Acidez total titulável - por titulação com hidróxido de sódio $(\mathrm{NaOH})$ devidamente padronizado, de acordo com o método 942.15, da $\mathrm{AOAC}^{1}$;

- Teor de proteínas - determinado pela técnica micro Kjeldahl, baseada em hidrólise e posterior destilação da amostra, de acordo com o método 31.1.08, da $\mathrm{AOAC}^{1}$; e

- Quantificação de cianeto total e livre.

Segundo a metodologia enzimática usada para a quantificação de cianeto, são incluídos, nessa dosagem, todos os compostos que contêm cianeto como a linamarina (glicosídeo cianogênico mais abundante na planta de mandioca) e precursores do processo de sua degradação como acetonacianoidrina e ácido cianídrico. As dosagens de cianeto total incluem a linamarina + acetonacianidrina $+\mathrm{HCN}$ e as de cianeto livre incluem somente o $\mathrm{HCN}^{7}$. A metodologia utilizada encontra-se resumida na Tabela 1. A leitura de absorbância foi realizada em espectrofotômetro da marca Varian, Cary 50 Bio - visível a 605 nm, com concentrações variando de 0,013 a 2,708 $\mu \mathrm{g} \mathrm{HCN.0,1} \mathrm{mL} \mathrm{mL}^{-1}$, totalizando 11 pontos para a construção da curva padrão.

\section{Resultados e discussão}

Os resultados da caracterização físico-química das 10 amostras de tucupi comercializadas na cidade de Belém PA estão expostos na Tabela 2.
A umidade de um alimento está relacionada com sua estabilidade, qualidade e composição e pode afetar tanto seu processamento, quanto sua embalagem e estocagem. Sendo o tucupi um alimento líquido, sua umidade se apresentou na faixa de 94,64 a $97,46 \%$, possuindo, portanto, de 5,36 a $2,55 \%$ de sólidos totais para tais valores. O teor de cinzas variou entre 0,18 e $1,08 \%$.

A acidez total das amostras analisadas variou entre 3,92 e 10,66 meq NaOH. $100 \mathrm{~mL}^{-1}$. Com relação ao teor de proteínas, o tucupi apresentou valores baixos, entre 0,33 e 0,66\%.

O tucupi se apresentou como um alimento de baixo $\mathrm{pH}$, variando entre 3,00 e 4,35, classificando-se como um alimento de alta acidez. A medida do pH é um parâmetro importante para a determinação de uma possível e rápida deterioração do produto, devido à presença e ao crescimento de microorganismos nocivos á saúde. Nos valores obtidos para o tucupi, há possibilidades do crescimento de bolores e leveduras.

$\mathrm{O}$ pH também determina a atividade das enzimas. Quando ocorre dilaceração dos tecidos vegetais das raízes de mandioca, em decorrência do seu processamento, o glicosídeo cianogênico linamarina presente é clivado em glicose e acetonacianoidrina, devido à ação catalisadora da enzima $\beta$-glicosidase (linamarase). Numa segunda e última etapa da cianogênese (processo de geração de $\mathrm{HCN}$ ), a acetonacianoidrina é convertida em HCN e acetona, e esta etapa pode ser mediada pela enzima hidroxinitriloliase numa faixa de $\mathrm{pH}$ de 3,5-6,0, ou ocorrer espontaneamente quando os valores de $\mathrm{pH}$ são maiores que 4,0. Assim sendo, pode-se observar que valores de $\mathrm{pH}$ ácidos ou próximos de uma faixa ácida contribuem para a cianogênese da linamarina, a exemplo das amostras de tucupi analisadas no presente estudo. Segundo NAMBISAN ${ }^{11}$, a enzima linamarase apresenta atividade máxima em pH entre 5,5-6,0. Sua natureza e atividade em tecidos vegetais são significativas, pois influenciam o grau de hidrólise dos glicosídeos cianogênicos durante o processamento e influem nos níveis finais de glicosídeos em produtos de mandioca.

Tabela 1. Metodologia de análise das formas de cianeto (total e livre) no tucupi.

\begin{tabular}{cccccccc}
\hline Cianeto & $\begin{array}{c}\text { Buffer } \\
\text { pH 7,0 }\end{array}$ & $\begin{array}{c}\text { Amostra } \\
\text { (extrato) }\end{array}$ & $\begin{array}{c}\text { Linamarase } \\
\left(15 \text { minutos } 30{ }^{\circ} \mathrm{C}\right)\end{array}$ & $\begin{array}{c}\text { NaOH 0,2 M } \\
(5 \text { minutos Repouso) }\end{array}$ & $\begin{array}{c}\text { Buffer } \\
\text { pH 6,0 }\end{array}$ & $\begin{array}{c}\text { Cloramina T } \\
\text { (agitar-gelo 5 minutos) }\end{array}$ & $\begin{array}{c}\text { Reagente de cor } \\
\text { (agitar-repouso 10 minutos) }\end{array}$ \\
\hline Total & $0,4 \mathrm{~mL}$ & $0,1 \mathrm{~mL}$ & $0,1 \mathrm{~mL}$ & $0,6 \mathrm{~mL}$ & $2,8 \mathrm{~mL}$ & $0,1 \mathrm{~mL}$ \\
Livre & $0,0 \mathrm{~mL}$ & $0,6 \mathrm{~mL}$ & $0,0 \mathrm{~mL}$ & $0,0 \mathrm{~mL}$ & $3,4 \mathrm{~mL}$ & $0,1 \mathrm{~mL}$ \\
\hline
\end{tabular}

Todas as análises descritas acima foram realizadas em triplicata.

Tabela 2. Caracterização físico-química das amostras de tucupi.

\begin{tabular}{|c|c|c|c|c|c|c|}
\hline Amostras & Umidade (\%) & Sólidos totais (\%) & Cinzas (\%) & Acidez (meq NaOH.100 mL $\mathrm{mL}^{-1}$ ) & $\mathrm{pH}$ & Proteínas (\%) \\
\hline $\mathrm{a}$ & e $95,05 \pm 0,00$ & b $4,95 \pm 0,00$ & ${ }^{\mathrm{c}} 0,70 \pm 0,01$ & ${ }^{\mathrm{f}} 4,23 \pm 0,00$ & ${ }^{\mathrm{a}} 4,35 \pm 0,01$ & ${ }^{\mathrm{a}} 0,61 \pm 0,01$ \\
\hline $\mathrm{b}$ & $\mathrm{a} 97,44 \pm 0,00$ & ${ }^{\mathrm{f}} 2,56 \pm 0,00$ & ${ }^{\mathrm{d}} 0,18 \pm 0,00$ & ${ }^{\mathrm{a}} 10,66 \pm 0,01$ & $\mathrm{~g} 3,46 \pm 0,01$ & ${ }^{\mathrm{de}} 0,41 \pm 0,01$ \\
\hline $\mathrm{c}$ & $\mathrm{a} 97,46 \pm 0,01$ & ${ }^{\mathrm{f}} 2,55 \pm 0,01$ & ${ }^{\mathrm{ab}} 0,97 \pm 0,06$ & ${ }^{\mathrm{e}} 4,30 \pm 0,00$ & de $3,66 \pm 0,00$ & ${ }^{\mathrm{de}} 0,41 \pm 0,01$ \\
\hline $\mathrm{d}$ & $\mathrm{f} 94,68 \pm 0,02$ & a $5,33 \pm 0,02$ & ${ }^{\mathrm{a}} 1,08 \pm 0,03$ & ${ }^{\mathrm{f}} 4,23 \pm 0,02$ & ${ }^{\mathrm{b}} 4,14 \pm 0,02$ & ${ }^{\mathrm{a}} 0,66 \pm 0,01$ \\
\hline $\mathrm{e}$ & ${ }^{c} 96,85 \pm 0,00$ & d $3,15 \pm 0,00$ & ${ }^{\mathrm{bc}} 0,75 \pm 0,04$ & ${ }^{\mathrm{f}} 4,23 \pm 0,03$ & ${ }^{\mathrm{f}} 3,55 \pm 0,01$ & ${ }^{\mathrm{cde}} 0,42 \pm 0,02$ \\
\hline $\mathrm{f}$ & $\mathrm{a} 97,41 \pm 0,00$ & ${ }^{\mathrm{f}} 2,59 \pm 0,00$ & ${ }^{\mathrm{bc}} 0,72 \pm 0,01$ & ${ }^{\mathrm{f}} 4,24 \pm 0,02$ & $\mathrm{~d} 3,71 \pm 0,01$ & ${ }^{\mathrm{cd}} 0,46 \pm 0,06$ \\
\hline $\mathrm{h}$ & d $96,69 \pm 0,01$ & ${ }^{c} 3,31 \pm 0,01$ & ${ }^{\mathrm{c}} 0,54 \pm 0,04$ & $\mathrm{~g} 3,92 \pm 0,01$ & ${ }^{c} 3,95 \pm 0,01$ & ${ }^{\mathrm{bc}} 0,51 \pm 0,02$ \\
\hline i & ${ }^{c} 96,91 \pm 0,03$ & $\mathrm{~d} 3,09 \pm 0,03$ & ${ }^{\mathrm{bc}} 0,74 \pm 0,12$ & ${ }^{c} 5,54 \pm 0,01$ & ${ }^{\mathrm{e}} 3,64 \pm 0,01$ & ${ }^{\mathrm{de}} 0,41 \pm 0,01$ \\
\hline $\mathrm{j}$ & $\mathrm{f} 94,64 \pm 0,03$ & a $5,36 \pm 0,03$ & ${ }^{\mathrm{ab}} 0,95 \pm 0,16$ & ${ }^{\mathrm{d}} 5,04 \pm 0,00$ & ${ }^{c} 3,97 \pm 0,03$ & ${ }^{\mathrm{ab}} 0,58 \pm 0,02$ \\
\hline
\end{tabular}

Os valores de uma mesma coluna, com a mesma letra, não diferem signnificativamente entre si (Teste de Tukey a 5\% de siơnificância). Média de três medições. 
Através dos resultados apresentados, verificam-se variações significativas entre as características físico-químicas das amostras em estudo, comprovando a falta de padronização do produto. De fato, o processo de fabricação do tucupi varia conforme o produtor, assim como a variedade da mandioca utilizada no processo de extração da manipueira.

Com relação à presença de cianeto nas amostras, pela Tabela 3, verifica-se que o teor de cianeto livre ficou na faixa de 9,47 a 46,86 mg HCN. $\mathrm{kg}^{-1}$, enquanto que o do cianeto total foi de 55,58 a 157,17 mg HCN. $\mathrm{kg}^{-1}$, apresentando variações significativas entre os produtos.

Tabela 3. Dosagem de cianeto total e livre nas amostras de tucupi.

\begin{tabular}{ccc}
\hline Amostras & Cianeto livre $\left(\mathrm{mg} \mathrm{HCN} \cdot \mathrm{kg}^{-1}\right)$ & Cianeto total $\left(\mathrm{mg} \mathrm{HCN}^{\mathrm{kg}}{ }^{-1}\right)$ \\
\hline $\mathrm{a}$ & ${ }^{\mathrm{c}} 38,03 \pm 0,13$ & ${ }^{\mathrm{a}} 157,17 \pm 0,00$ \\
$\mathrm{~b}$ & ${ }^{\mathrm{h}} 9,47 \pm 0,13$ & ${ }^{\mathrm{e}} 103,87 \pm 0,00$ \\
$\mathrm{C}$ & ${ }^{\mathrm{d}} 35,41 \pm 1,14$ & ${ }^{\mathrm{c}} 119,26 \pm 2,05$ \\
$\mathrm{~d}$ & ${ }^{\mathrm{a}} 46,70 \pm 0,14$ & ${ }^{\mathrm{a}} 152,39 \pm 1,70$ \\
$\mathrm{e}$ & ${ }^{\mathrm{e}} 31,94 \pm 0,35$ & ${ }^{\mathrm{b}} 126,25 \pm 2,13$ \\
$\mathrm{f}$ & ${ }^{\mathrm{b}} 42,43 \pm 0,32$ & ${ }^{\mathrm{g}} 72,40 \pm 1,94$ \\
$\mathrm{~g}$ & ${ }^{\mathrm{g}} 14,67 \pm 0,08$ & ${ }^{\mathrm{h}} 55,58 \pm 1,01$ \\
$\mathrm{~h}$ & ${ }^{\mathrm{f}} 18,86 \pm 0,00$ & ${ }^{\mathrm{g}} 67,38 \pm 2,01$ \\
i & ${ }^{\mathrm{a}} 44,86 \pm 0,14$ & ${ }^{\mathrm{f}} 95,11 \pm 0,85$ \\
j & ${ }^{\mathrm{a}} 46,86 \pm 1,08$ & ${ }^{\mathrm{d}} 111,32 \pm 2,67$ \\
\hline
\end{tabular}

Os valores de uma mesma coluna, com a mesma letra, não diferem significativamente entre si (Teste de Tukey a 5\% de significância). Média de três medições.

De fato, o processo de fabricação da farinha de mandioca que leva à geração do tucupi pode dar origem a produtos diferenciados com relação aos teores de cianeto em dependência de alguns fatores, como: a forma como o processo ocorre, se manual (uso do tipiti) ou mecanizado; tipo de cultivar; idade da planta; tipo de solo; entre outros. Todos esses fatores podem originar plantas com diferentes concentrações de ácido cianídrico. Mais uma evidência para essas diferenças está no fato de que as raízes usadas para a produção de farinha de mandioca são raízes com alto teor de ácido cianídrico, isto é, são usadas raízes classificadas como mandiocas bravas, as quais gerarão, conseqüentemente, um tucupi também com valores elevados de ácido cianídrico, caso o processo de destoxificação natural não seja eficaz.

Segundo HOSEL e BARZ ${ }^{8}$, cerca de $70 \%$ da linamarina presente na raiz da mandioca é removido por hidrólise enzimática durante o processamento. Em complementação, quase todo o cianeto que é gerado é removido por volatilização ou solubilização ${ }^{10}$.

Com relação aos teores de cianeto em raízes de mandioca, alguns autores citam em seus trabalhos a problemática de serem ingeridas raízes cruas ou mal processadas. DUFOUR ${ }^{6}$ cita a existência de raízes de mandioca com altos teores de ácido cianídrico ao analisar etnovariedades de mandiocas da Amazônia, constatando valores variando de 311 a $508 \mathrm{mg} \mathrm{HCN. \textrm {kg } ^ { - 1 }}$ de raiz fresca, com média de $454 \mathrm{mg} \cdot \mathrm{kg}^{-1}$, consideradas como altamente tóxicas.

Neste trabalho, foram quantificados os teores de cianeto presentes no tucupi que é um produto da industrialização da mandioca muito usado no norte do Brasil. Assim sendo, quantificar os teores de cianeto previamente em raízes de mandioca torna-se muito importante no caso de posterior ingestão de produtos crus ou mal processados, pois a linamarina remanescente, não hidrolizada, que sobra desse processamento das raízes, poderá causar problemas de saúde quando esse residual for hidrolizado no corpo humano ou animal, liberando cianeto livre $(\mathrm{HCN})^{14,2}$.

Baseando-se na classificação das raízes de mandioca quanto ao teor de cianeto, citado por BOURDOUX et al. ${ }^{3} \mathrm{e}$ comparando-se esta com os valores obtidos pelo atual trabalho com relação ao tucupi, os valores de cianeto total encontrados em $60 \%$ das amostras de tucupi apresentam-se elevados.

Levando-se em conta que o produto tucupi adquirido nas feiras e supermercados geralmente é submetido a processo de fervura pelos consumidores antes de ser ingerido, essas concentrações, apesar de serem altas, não têm ocasionado relatos pelos consumidores de problemas a sua saúde. Isso porque, quando o tucupi é submetido a altas temperaturas, ocorre uma hidrólise mais acentuada dos compostos ciânicos e conseqüente volatilização das formas de cianeto livre (HCN) para o ambiente.

\section{Conclusões}

De acordo com os resultados apresentados, conclui-se que não há uma padronização nas características físico-químicas do tucupi comercializado, fazendo-se necessária a realização de estudos para a elaboração de uma proposta visando a sua padronização e proporcionando um produto de melhor qualidade ao consumidor. Tornam-se necessárias também melhorias no processo de fabricação do tucupi visando à redução do teor de cianeto, uma vez que $60 \%$ das amostras analisadas apresentaram teor de cianeto total superior a $100 \mathrm{mg} \mathrm{HCN} . \mathrm{kg}^{-1}$.

\section{Agradecimentos}

Os autores agradecem ao Fundo Estadual de Ciência e Tecnologia - FUNTEC, Governo do Estado do Pará, pelo apoio financeiro.

\section{Referências bibliográficas}

1. AOAC. Official methods of analysis of the Association of Official Analytical Chemists: edited Ig W. Horwitz $16^{\mathrm{a}}$ ed. Washington, 850 p, v. 2, 1997.

2. BALAGOPALAN, C. et al. Cassava in food. Feed and Industry. CRCPress, Boca Raton, FL., 1988.

3. BOURDOUX, P. et al. In: ___ Nutritional factors involved in the goitrogenic action of cassava. Ottawa, qnt, IDRC, 1982. 100 p: ill.

4. CAGNON, J. R.; CEREDA, M. P.; PANTAROTTO, S. In: Cd-rom. Série: Cultura de tuberosas amiláceas latino-americanas. v. 2 - Cultura de tuberosas amiláceas latino-americanas. Fundação Cargill, São Paulo, Brasil, Ago/2002.

5. CARDOSO, C. E. L. et al. Eficiência econômica e fatores que afetam a competitividade da cadeia agroindustrial da mandioca. In: VIEIRA, R. C. M. T. et al. Cadeias produtivas no Brasil: análise de competitividade. Brasília: Embrapa Comunicação 
para Transferência de tecnologia. Secretaria de Administração Estratégica, 2001. 468 p.

6. DUFOUR, D. L. Cyanide contento $\mathrm{f}$ cassava (Manhiot esculenta, Euphorbiaceae) cultivars used by Tukanoan Indians in Northwest Amazônia. Economy Botany, New York, v. 42, n. 2, p. 255-266, 1988.

7. ESSERS, A. J. A. et al. Assay for the cyanogens content in cassava products. (Preliminary Version, December, 1993). Department of food Science, Wageningen. Agricultural University, Netherlands. 9 p.

8. HOSEL, W.; BARZ, W. $\beta$-glucosidases from Cicer arientum L. Eur. Journal Biochemistry, v. 57, n. 2, p. 607-616, 1975.

9. IBGE - Instituto Brasileiro de Geografia e Estatística. Pesquisa de Orçamento Familiar, 1987/88. Rio de Janeiro, 1991.

10. IKEDIOBI, C.; ONYIA, G.; ELUWAH, C. A rapid inexpensive enzymatic assay for total cyanide in cassava products. Agrc. Biol. Chem, v. 44, n. 12, p. 2803-2809, 1980.
11. NAMBISAN, B. Evaluation of the effect of various processing techiniques on cyanogens content redustion in cassava. In: BOKANGA, M. et al. Acta Horticulturae - International Workshop on Cassava Safety. Tbadan: WOCAS, v. 375, p. 203-207, 1994.

12. OSUNTOKUM, B. O. Cassava diet, chronic cyanide intoxification and neuropathy in Nigerian Africans. World Review of Nutrition and Dietetics, v. 36, n.1, p. 141-173, 1981.

13. ROSLING, H. Measuring effects in humans of dietary cyanide exposure from cassava. Acta Horticulturae: International Workshop on Cassava Sofety, v. 376, p. 271-83, 1994.

14. TEWE, O. Cyanogenic glycoside, protein interaction in cassava peel based rations. Nutr. Rep. Int. v. 30, p. 425-431, 1984.

15. TYLLESTAR, T. Cassava cyanogens and Konzo, an upper motoneuron disease found in Africa. Lancet, n. 339, p. 208-211, 1992. 